\title{
A Consult Is Just a Page Away: A Prospective Observational Study on the Impact of Jinxing on Call Karma in Neurosurgery
}

\author{
Holger Joswig, Lauren Zarnett, David A. Steven, Martin N. Stienen
}

\begin{abstract}
Objective: Our aim was to assess the impact of jinxing on "call karma" in neurosurgery. Methods: We conducted a prospective observational study on 15 residents on call for the neurosurgery service, recording the total number of admissions, consults, deaths encountered, surgeries performed, hours of sleep and subjective call rating on a numeric rating scale (NRS) of 0-10 in terms of general awfulness. Results: Some 204 on-call nightshifts were analyzed, of which 61 (29.9\%) were jinxed and 143 (70.1\%) were nonjinxed. Jinxes seemed to occur in clusters. The baseline parameters (experience, type of call coverage and superstition level) of the study groups were well balanced. A trend toward more surgeries was observed during jinxed nights, where residents slept significantly less (mean $147.8 \pm 96.2$ vs. $180.9 \pm 106.1 \mathrm{~min}, p=0.037$ ) and rated their on-call experience worse on the NRS $(4.4 \pm 2.2$ vs. $3.5 \pm 2.0$, $p=0.011$ ), while there was no significant difference in number of admissions, consults or deaths. Conclusions: The act of jinxing ought to be avoided in the neurosurgical setting, as it might be potentially harmful to resident call karma, irrespective of level of experience, resources and personal beliefs.
\end{abstract}

RÉSUMÉ: Quand la guigne s'acharne: étude observationnelle prospective quant à l'impact de l'idée de mauvais sort au sein d'un service de neurochirurgie. Objectif: Notre objectif est ici d'évaluer l'impact de l'idée de « mauvais sort » au sein d'un service de neurochirurgie. Méthodes: Pour ce faire, nous avons mené une étude observationnelle prospective portant sur 15 médecins résidents travaillant sur appel. Nous avons ainsi noté, outre le temps de sommeil de ces médecins, le nombre total d'admissions, de consultations, de décès et d'opérations chirurgicales réalisées. En fonction d'une échelle de 0 à 10, nous avons aussi cherché à évaluer le caractère négatif de leur expérience vécue au cours de leur quart de travail. Résultats: 204 quarts de nuit sur appel ont été analysés. De ce nombre, $61(29,9 \%)$ comportaient une dimension marquée par le mauvais sort tandis que les 143 autres (70,1\%) n'en comportaient aucune. Il semble que les quarts de nuit marqués par le mauvais sort avaient tendance à se produire en «grappes ». À noter que nos principaux paramètres d'étude (l'expérience, le type d'interventions, les superstitions de chacun) étaient bien équilibrés. Une tendance à l'augmentation du nombre d'opérations chirurgicales a été notée durant ces quarts de nuit perçus comme marqués par le mauvais sort, quarts durant lesquels les médecins résidents dormaient beaucoup moins (moyenne de 147,8 \pm 96,2 contre 180,9 $\pm 106,1 \mathrm{~min} ; \mathrm{p}=0,037$ ) et attribuaient, en fonction de l'échelle évoquée ci-dessus, un moins bon score quant à leur expérience vécue $(4,4 \pm 2,2$ contre $3,5 \pm 2,0 ; p=0,011)$. Fait à souligner, aucune différence notable n'a été observée en ce qui concerne le nombre d'admissions, de consultations et de décès. Conclusions: Le fait de nourrir cette perception d'un mauvais sort devrait être évité dans un environnement de travail neurochirurgical. Cela peut en effet potentiellement nuire à l'intervention d'un médecin résident, et ce, peu importe son niveau d'expérience, les ressources dont il dispose et ses croyances personnelles.

Keywords: Call karma, jinx, neurosurgery, superstition

doi:10.1017/cjn.2016.457

Can J Neurol Sci. 2017; 44: 420-423

\section{INTRODUCTION}

Superstition and magical thinking are pervasive and entrenched even among intelligent, educated and emotionally stable adults. ${ }^{1}$ In view of the literature, ${ }^{2-7}$ acquaintance with irrational concepts such as "jinxing" seems to predominate the perception of being on call by healthcare professionals. The definition of "jinx" or "jinxing" (see Figure 1 legend for etymology), however, is not unequivocal. According to the Urban Dictionary, "a jinx [noun] is something or someone that is considered to be unlucky or to bring bad luck." There is a body of literature ${ }^{3,5-7}$ on doctors who seemingly attract dreadful on-calls enriched with multiple consults and no sleep. These unlucky individuals in the healthcare system are oftentimes referred to as "black clouds," as opposed to their lucky counterparts, the "white clouds." Whereas in view of negative findings by these authors ${ }^{3,5-7}$ the cloud concept can safely be consigned to history, the impact on call karma by actively

From the Department of Clinical Neurological Sciences, Division of Neurosurgery, London Health Sciences Centre, University Hospital, London, Ontario, Canada (HJ, LZ, DAS);

Department of Neurosurgery, University Hospital Zurich, Zurich, Switzerland (MNS). Received November 15, 2016. Final Revisions Submitted November 27, 2016. Date of Acceptance November 28, 2016.

Correspondence to: Holger Joswig, Department of Clinical Neurological Sciences, Division of Neurosurgery, London Health Sciences Centre, University Hospital, 339 Windermere Road, London, Ontario, Canada N6A 5A5. Email: holger.joswig@gmail.com. 


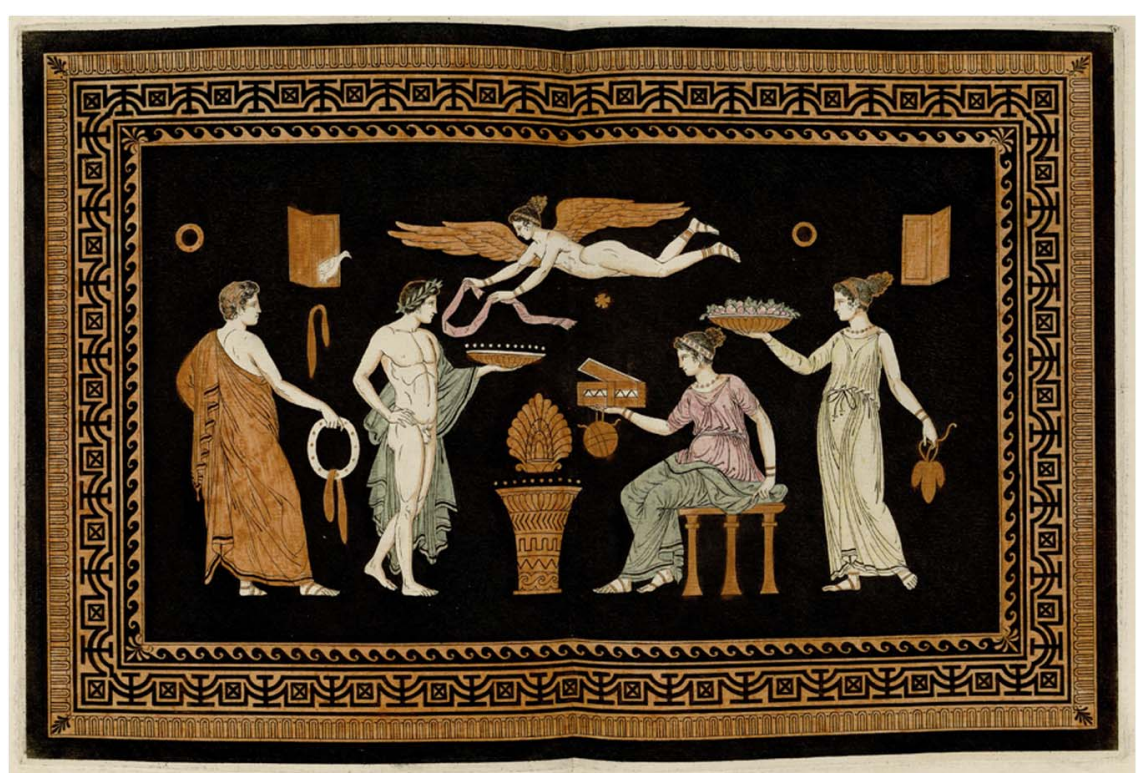

Figure 1: Iynx (middle) in Greek mythology. Courtesy print by the Department for Rare Prints of Göttingen State and University Library, Germany, of the book "Antiquités Etrusques, Grecques Et Romaines: Tirées du Cabinet de M. Hamilton Envoyé Extraordinaire de S.M. Britannique en Cour de Naples," by Pierre Francois Hugues Hancarville (1766). ${ }^{10}$ According to The Dictionary of Greek and Roman Biography and Mythology, ${ }^{11}$ the Greek nymph Iynx, a daughter of Peitho and Pan, or of Echo, cast a spell on Zeus to make him fall in love with Io. This, in return, prompted Hera to metamorphose Iynx into the bird called iynx. Nowadays, the bird iynx torquilla (Eurasian wryneck) is considered a symbol of bad luck for its ability to turn its head around 180 degrees.

"jinxing" [verb] the on-call person, that is, "to give bad luck" according to the Urban Dictionary, ${ }^{8}$ is less clear. Hence, the current study prospectively assessed on-call outcome parameters (here referred to as "call karma") in unintentionally jinxed residents on a neurosurgery service.

\section{Methods}

The neurosurgery junior and off-service residents performing (senior resident covered or uncovered) first on-call at the Department of Clinical Neurological Sciences at the Health Sciences Centre of Western University (London, Ontario) between 13 January 2016 and 12 August 2016 were recruited and gave their written consent for participation. On enrolment, all participating residents rated their baseline level of superstition on a scale from 1 (least) to 5 (most), as done by Ahn et al. ${ }^{2}$

\section{Jinxed or Nonjinxed Nights}

Before or shortly after the beginning of the on-call nightshift (5:00 p.m. to 8:00 a.m.), the residents noted whether or not and how often they were jinxed by any healthcare professional (resident, staff consultant or nurse) during the previous daytime. The criteria for a positive jinx were met when such encouragements as "I hope you have a quiet night" were given to the resident and when they felt genuinely jinxed by that.

\section{Recorded Parameters}

The morning after, residents reported the following on-call parameters: number of admissions, consults, number of deaths encountered, number of surgeries stratified into the three in-house established urgency categories $(\mathrm{A}<2 \mathrm{~h}$; B within 2-8h; and $\mathrm{C}$ within $8-48 \mathrm{~h}$ ), hours of sleep, and subjective rating of the nightshift on a numeric rating scale (NRS) ranging from 0 (comparable to sleeping at home in your own bed with no pager) to 10 (worst) in terms of general awfulness.

\section{Statistical Considerations}

Jinxed nightshifts were compared to those that were not jinxed, and study groups were built accordingly. As the resident's level of experience, the presence or absence of a senior resident as backup and the individual's tendency to superstition may represent potential confounders to the research question, these parameters were checked for imbalances. The dependent variables were the total numbers of admissions, consults, deaths, surgeries and hours of sleep, and NRS scores. Variables on a continuous scale were compared using Student's $t$ test or rank-sum tests, depending on a normal distribution of results. Values of $p<0.05$ were considered statistically significant. Stata (v. 14; College Station, TX, USA) was employed for analysis.

\section{Patient Involvement}

No patients were involved in setting the research question or the outcome measures, nor were they involved in the design and implementation of the study. There are no plans to involve patients in dissemination.

\section{Results}

A total of 15 junior residents ( 7 neurosurgery residents and 8 off-service residents) provided post-call outcome data from 213 nightshifts. Total missing data due to loss of follow-up in the 


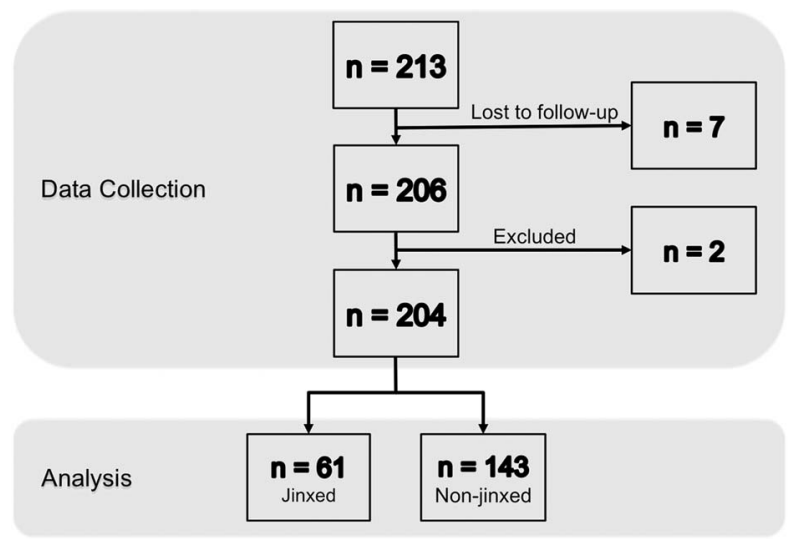

Figure 2: Flowchart of data collection and analysis from 213 jinxed and nonjinxed on-call nightshifts.

morning was 7 (3.3\%), and using the case-deletion method to deal with this, 206 complete datasets were available. From this, two nonjinxed calls were excluded, as distinct events other than jinxing were responsible for terrible nightshifts with no sleep: a feverous infection in one resident and another resident running behind schedule for his grand rounds presentation that was due the following morning. Thus, the final statistical analysis was performed for 204 nightshifts. A flowchart of the data collection and analysis is provided in Figure 2.

During the study interval, the residents were jinxed on $61(29.9 \%)$ occasions, with an average of 1.39 times $(S D=0.86$; range $=1-5$ times) on the same shift, and this seemed to occur in clusters (Figure 3). Overall, they admitted or consulted on 527 patients, encountered 37 deaths, performed 54 surgeries $(10 \mathrm{~A}$, $25 \mathrm{~B}$ and $19 \mathrm{C}$ cases), gained a total of $537 \mathrm{~h}$ of sleep, and rated their on-call awfulness as 3.83 on average $(S D=2.10$; range $=0-9)$.

Table 1 shows the well-balanced baseline demographic data in terms of level of experience, call coverage and superstition preload between jinxed and nonjinxed nightshifts.

The post-call outcome parameters are shown in Table 2. Residents reported an approximately 30-minute reduction in sleep during jinxed calls $(p=0.037)$ and a higher degree of awfulness in their subjective rating of a jinxed call night $(4.4 \pm 2.2$ vs. $3.5 \pm 2.0, p=0.011$ ). While there was no significant difference in the number of admissions, consultations or deaths between jinxed and nonjinxed nightshifts, a trend toward more surgeries during jinxed nightshifts was registered.

\section{Discussion}

In this prospective observational study of junior residents on call for the neurosurgery service over a period of seven months, jinxing status was associated with a significant effect on

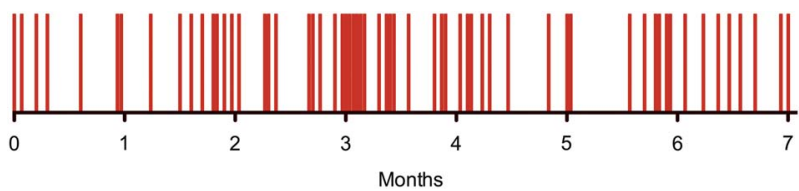

Figure 3: Jinxed on-call nightshifts (red bars) appeared to come in clusters during an observation period of seven months in the neurosurgery service.
Table 1: Baseline demographic data of 206 jinxed and nonjinxed neurosurgery on-call nightshifts

\begin{tabular}{l|c|c|c}
\hline & Jinxed & Nonjinxed & Value of $\boldsymbol{p}$ \\
\hline Level of experience & & & 0.127 \\
\hline PGY 1 & $8(13.1 \%)$ & $36(25.2 \%)$ & \\
\hline PGY 2-3 & $43(70.5 \%)$ & $82(57.3 \%)$ & \\
\hline Off-service & $10(16.4 \%)$ & $25(17.5 \%)$ & \\
\hline Call coverage & & & 0.713 \\
\hline Senior back-up & $35(57.4 \%)$ & $86(60.1 \%)$ & \\
\hline Solo call & $26(42.6 \%)$ & $57(39.9 \%)$ & \\
\hline Resident superstition level & & & 0.207 \\
\hline Low (1-2) & $58(95.1 \%)$ & $124(86.7 \%)$ & \\
\hline Medium (3) & $1(1.6 \%)$ & $5(3.5 \%)$ & \\
\hline High (4-5) & $2(3.3 \%)$ & $14(9.8 \%)$ & \\
\hline & $n=61(100 \%)$ & $n=143(100 \%)$ & \\
\hline
\end{tabular}

Results are presented in count (percent). PGY = postgraduate year.

The resident superstition level was rated according to the five-tier scale proposed by Ahn et al. ${ }^{2}$

their subjective perception of the call. While the NRS of call awfulness is a subjective outcome measure, other (more objective) parameters of badness such as the number of admissions, consultations and deaths were more evenly distributed between jinxed and nonjinxed nights. A trend of a higher incidence of surgeries during jinxed nights was noted, and it warrants mentioning that surgical involvement during call can be interpreted as beneficial for training from a neurosurgery trainee's perspective. Whether the observed statistically significant lack of sleep, which in a previous study on "black clouds" was identified as a major predictor of perceived workload, during a jinxed night is directly related to the curse or indirectly related to a provoked fear of falling asleep secondary to jinxing cannot be answered with the present data.

In 2002, Ahn et al. ${ }^{2}$ conducted a randomized controlled trial of 30 medical house officers at two university-affiliated medical centres that yielded contrary findings. Paradoxically, jinxed

Table 2: Post-call outcome assessment of 206 jinxed and nonjinxed neurosurgery on-call nightshifts, with results presented in count (percent) or mean (standard deviation)

\begin{tabular}{l|c|c|c}
\hline & Jinxed & Nonjinxed & Value of $\boldsymbol{p}$ \\
\hline Admissions/consults & $2.77(1.75)$ & $2.50(1.81)$ & 0.331 \\
\hline Deaths & $0.23(0.46)$ & $0.16(0.45)$ & 0.163 \\
\hline Surgeries & $0.38(0.61)$ & $0.23(0.44)$ & 0.055 \\
\hline Urgency level & & & \\
\hline A cases & $3(4.9 \%)$ & $7(4.9 \%)$ & 0.994 \\
\hline B cases & $10(16.4 \%)$ & $15(10.5 \%)$ & 0.239 \\
\hline C cases & $7(11.5 \%)$ & $12(8.4 \%)$ & 0.488 \\
\hline Sleep (minutes) & $147.8(96.2)$ & $180.9(106.1)$ & 0.037 \\
\hline On-call rating & $4.4(2.2)$ & $3.5(2.0)$ & 0.011 \\
\hline
\end{tabular}


residents had significantly fewer admissions and more hours of sleep, and reported a lower subjective level of difficulty than nonjinxed residents. ${ }^{2}$ The authors could not satisfactorily explain the favourable "jinx effect," but prematurely concluded that encouraging remarks to residents when on call can safely be offered. ${ }^{2}$ However, despite being otherwise well-designed, the study of Ahn et al. ${ }^{2}$ was performed over a short period of only 69 nights and had a major methodological flaw: randomisation (jinxing) was done by unlabeled envelopes containing either the jinx message, which was read out loud to the unfortunate resident, or a blank form. Clearly, a genuine jinx cannot be sent purposefully. While randomized controlled trials represent the gold standard in evidence-based medicine, ${ }^{9}$ paranormal phenomena such as bad luck can only be investigated in a methodologically correct way in a prospective observational manner.

After all, jinxing status remains ill-defined and subjective. It cannot be ruled out that post-call residents after an extraordinary terrible night retrospectively acknowledged a false-positive jinx event. Furthermore, some might feel jinxed more easily than others depending on differences in experience, available resources, personal beliefs and cultural factors. Postgraduate year or off-service status, type of call coverage and superstition level did not turn out to be confounders in the current study. However, our results should only be carefully extrapolated to differently organized institutions and other medical specialties with different work cultures. The impression that jinxed nights accumulated in clusters over the months (Figure 3 ) is puzzling. To explain this periodicity, in future studies with larger data volumes it might be worthwhile to assess for a correlation of jinxing with geophysical cycles that are known to influence the activity of life on earth, ${ }^{4}$ or other phenomena.

Quantitative and qualitative means of being on-call are not well-validated. While the current study and the study of Ahn et al. utilize important objective measures of on-call difficulty and awfulness, these carry uncertainties ${ }^{7}$ and are influenced by a multitude of factors in the hospital environment. For example, the post-call assessment did not take into account the difficulty level of a patient encounter, demanding family members, the magnitude of tragedy of some cases or the number of pages by the floor nurses that interrupted one's sleep. We integrated an NRS of call awfulness rather than difficulty as proposed by Ahn et al. ${ }^{2}$ in an attempt to better sum up the aforementioned factors. Certainly, this scale requires further validation; some might even argue that no outcome parameters can ever express what being on call really feels like.

Despite these methodological challenges, important conclusions can be drawn from the results of this study, which, to the best of our knowledge, is the largest study in the jinxing literature. In the medical world, jinxing colleagues-intentional or notshould be minimised in order to not negatively affect the respective healthcare provider's well-being and sleep. The question of whether or not jinxing behaviour in turn jeopardises patients' best medical care was not addressed by our research group. Looking at complications and patients' outcomes in future studies would shed more light on this. However, further research in this field should only be conducted under strict ethical supervision in view of the present findings.

\section{CONCLUSION}

Jinxing may have a negative impact on resident call karma, irrespective of level of experience, resources and personal beliefs. Our data would suggest that, at least in the neurosurgical setting, jinxing ought to be avoided prior to resident call shifts.

\section{ACKNOWLEDGEMENTS}

The authors thank Abdul Naeem, Aisha Ghare, Ali Bateman, Benjamin van der Woerd, Caitlin Ward, David Kim, Idara Edem, Enriqueta Lucar-Figueroa, Jacqueline Cox, Kiersten Pianosi, Lauren Zarnett, Michael Staudt, Ryan Taylor, Stuart McGregor and Vahagn Karapetyan for sharing their on-call experience with the scientific community.

\section{Disclosures}

Holger Joswig, Lauren Zarnett, David Steven and Martin Stienen hereby declare that they do not have anything to disclose.

\section{STATEMENT OF AUTHORSHIP}

HJ: study conceptualization, data collection, manuscript drafting/finalization, literature research, creation/edit of Figures 1-3. LZ: study conceptualization, data collection, manuscript review. DAS: manuscript review, study supervision. MNS: statistics, creation of Tables 1 and 2, manuscript review.

\section{REFERENCES}

1. Risen JL. Believing what we do not believe: acquiescence to superstitious beliefs and other powerful intuitions. Psychol Rev. 2016;123(2):182-207; Epub ahead of print Oct 19, 2015.

2. Ahn A, Nallamothu BK, Saint S. "We're jinxed": are residents' fears of being jinxed during an on-call day founded? Am J Med. 2002;112(6):504. Available at: http://www.amjmed.com/article/ S0002-9343(01)01128-7/pdf.

3. Fabre A, Mancini J. Jinx or not?: There is nothing like a "black cloud" syndrome. Pediatr Emerg Care. 2016. Epub ahead of print Feb 6.

4. Foster RG, Roenneberg T. Human responses to the geophysical daily, annual and lunar cycles. Curr Biol. 2008;18(17):R784-94; Available at: http://www.cell.com/current-biology/fulltext/S09609822(08)00865-8.

5. Meyr AJ, Gonzalez O, Mayer A. Quantification and perception of on-call podiatric surgical resident workload. J Foot Ankle Surg. 2011;50(5):535-6; Epub ahead of print Jun 11.

6. Tanz RR, Charrow J. Black clouds: workload, sleep, and resident reputation. Am J Dis Child. 1993;147(5):579-84.

7. Walling HW. Actual versus perceived workload for house officers: black cloud looming? Ann Intern Med. 2004;140(10):847-8.

8. Urban Dictionary. Available at: http://www.urbandictionary.com/ define.php?term $=$ jinx

9. Guyatt GH, Oxman AD, Kunz R, et al. What is "quality of evidence" and why is it important to clinicians? BMJ. 2008;336(7651):995-8.

10. Antiquités Etrusques, Grecques et Romaines: Tirées du Cabinet de M. Hamilton Envoyé Extraordinaire de S.M. Britannique en Cour de Naples. Göttingen State and University Library, Department for Rare Prints, Germany.; 1766. Available at: http://gdz.sub.unigoettingen.de/dms/load/img/?PID=PPN684918862\%7CLOG_00 22\&physid=PHYS_0420.

11. Dictionary of Greek and Roman Biography and Mythology, by various writers. New York: Little, Brown and Company; 1867. Available at: http://quod.lib.umich.edu/m/moa/acl3129.0002.001/ 702 ?view $=$ image $\&$ size $=100$. 